\title{
Longitudinally Extensive Transverse Myelitis (LETM) secondary to SARS-CoV-2 infection - A recent reality in spinal cord injury rehabilitation
}

João Fonseca ${ }^{1}$, Alexandra Coelho ${ }^{2}$, Ana Lourenço ${ }^{3}$, César Pires ${ }^{4}$, and Paulo Margalho ${ }^{4}$

${ }^{1}$ Centro Hospitalar e Universitário de Coimbra EPE

${ }^{2}$ Centro Hospitalar e Universitario de Coimbra EPE

${ }^{3}$ Centro de Medicina de Reabilitacao da Regiao Centro Rovisco Pais

${ }^{4}$ Centro de Medicina de Reabilitação da Região Centro Rovisco Pais

February 11, 2022

\begin{abstract}
Transverse myelitis can be a complication of SARS-CoV-2 infection. We report the case of transverse myelitis related to SARS-CoV-2 infection. Beyond the disease itself, neurological involvement affects functionality. In this situation, Physical and Rehabilitation Medicine plays a crucial role in managing patient rehabilitation.
\end{abstract}

\section{Hosted file}

Longitudinally Extensive Transverse Myelitis (LETM) related with SARS-CoV-2 infection -- A new reality available at https://authorea.com/users/460035/articles/556118-longitudinally-extensivetransverse-myelitis-letm-secondary-to-sars-cov-2-infection-a-recent-reality-in-spinalcord-injury-rehabilitation

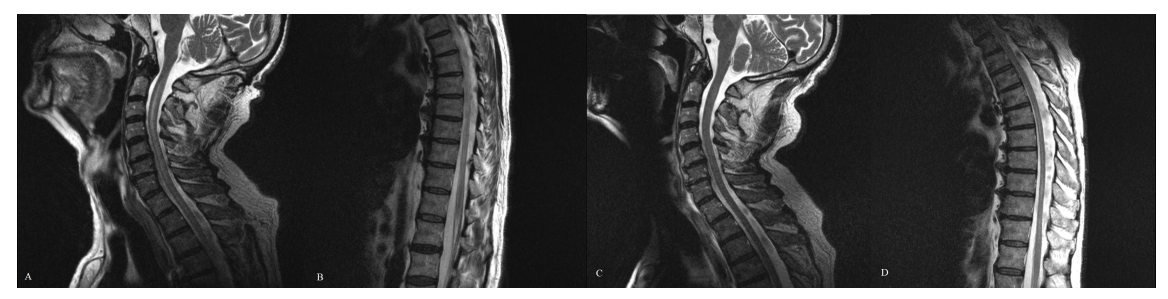

